\title{
The human factor
}

\author{
Paucity of information on the potentially complex responses of individuals and societies to climate \\ change policies is a barrier to effective action.
}

Understanding climate change has traditionally been the domain of natural science. Climatologists and modellers along with other researchers in the Earth sciences have documented past and present climate and established underlying mechanisms. Although many uncertainties persist, there is now a wide scientific consensus that our activities are changing the global climate. It is also widely appreciated - not least at the governmental level - that future climate change has the potential to impact humanity, both directly and indirectly, posing large and complex challenges to the ways that societies operate and are governed.

Largely, it is this realization that documenting the nature of the 'problem' is only the start of the challenge of resolving it that has led to an upsurge in interest from the social scientists who seek, among many other things, to understand peoples' perceptions of climate change risks, what it will take to change behaviours, and the roles that science education and communication should play. At the same time, economists are trying to get to grips with the effectiveness of carbon trading as a mitigation strategy, how rich nations will help the developing world adapt, and indeed whether standard economic models will remain viable into the future. Meanwhile, politicians grapple with how to translate all of this into action, and how to sell often controversial policies to the people they represent.

Understanding climate change is one thing, but doing something about it is quite another. This transition from knowledge to action requires a deep understanding of the human condition. Several contributions in this issue of Nature Climate Change focus on human aspects of climate change. Some may be controversial, but all are worth readers' attention.

On page 596, Joseph Aldy and colleagues assess potential voter support for the National Clean Energy Standard (NCES) proposed by American President Barack Obama, which is designed to deliver $80 \%$ 'clean energy' by 2035 . To assess public attitudes towards the proposal, the researchers analyse the results of a nationally representative survey of around 1,000 Americans of voting age along with additional information obtained through the
US census; the rationale for the approach and how it has been used previously in economics are discussed in an accompanying News \& Views article by Michael Hanemann (page 573). In stark contrast to the prevailing political deadlock over the issue, Aldy and colleagues find broad support for a renewable energy standard among the public, albeit with differences associated with gender, age and political affiliation. The results also show that the amount people would be willing to pay depends on the proposed energy mix, renewables alone being favoured over mixes that also include natural gas or nuclear power. The researchers conclude that legislation could pass through both chambers of Congress with relative ease, provided that voters can be convinced that average electricity bill increases can be kept below $5 \%$, which will certainly encourage advocates of the proposed clean energy standard.

Moving to international negotiations, Florian Landis and Thomas Bernauer (page 628) combine climate and economic modelling to estimate how much compensation the richer countries of the OECD (Organisation for Economic Cooperation and Development) would have to give poorer countries to persuade them to accept a realistic uniform carbon price as part of the global mitigation effort. Any agreement could well involve transfer of tens of billions of US dollars a year from rich industrialized counties to developing nations and emerging economies. However, this is more or less in line with amounts discussed previously at 'Conference of the Parties' meetings of the United Nations Framework Convention on Climate Change, the most recent of which was held in Durban in November 2011. Landis and Bernauer hope, however, that their analysis will put such estimates on a firmer and more rigorous footing, while also arguing that a global bargain should be achievable.

A detailed understanding of the various ways in which human activities lead to greenhouse-gas emissions and the relative importance of these pathways is widely considered necessary for prioritizing mitigation actions and policies. In their review of the literature in this area (page 581), Eugene Rosa and Thomas Dietz define anthropogenic drivers of climate change as the "range of human actions that cause climate change and the factors that shape those actions". A range of such drivers are considered by the researchers, with a focus on emissions at the level of nations. They concur with the often stated view that human population growth itself has a consistent impact on greenhouse-gas emissions, but also highlight the effects of the number of households (as against population per se), age structure, and the actual rate of population increase. They next look at how patterns of consumption change as people become more affluent, and how this tends also to increase emissions despite tempering factors such as increased use of renewable energy sources and adoption of policies seeking to minimize environmental damage. Based on existing evidence, Rosa and Dietz are not convinced that continued increases in affluence eventually lead to declining stress on the environment as predicted by the so-called environmental Kuznets curve hypothesis, except perhaps at the local level. They also find the existing evidence concerning urbanization, culture and institutions ambiguous, suggesting the need for further investigation into their possible significance as drivers of emissions.

Of course, there are many people who question whether human activities are having a significant effect on climate, or whether future climate change - if it occurs - will be as dangerous as many fear. Many of these doubters are simply sceptical about the existing evidence as they understand it. Others, however, seem to take a more overtly contrarian view. Either way, it is interesting to ask whether and under what circumstances people who are unconvinced that anthropogenic climate change is occurring would support pro-environmental measures, even if primarily designed to mitigate climate change. This is just what Paul Bain and colleagues (page 600) set out to do. Their laboratory-based study suggests that in many cases these individuals would be more supportive of such measures if they believe the actions would have other tangible societal or economic benefits. Commenting on the findings, Paul Stern (page 572) argues that societies need to consider how environmental policy decisions may affect individual and societal values, and reminds us that these choices will affect us all. 